\title{
RANCANG BANGUN SISTEM INFORMASI KELAYAKAN BANTUAN SOSIAL COVID 19 BERBASIS WEB DI DESA TAPOS
}

Title as few words as possible, describing the content Articles Accurately

\author{
${ }^{1}$ Nurhayati, ${ }^{2}$ Sri Mulyati \\ ${ }^{1,2}$ Program Studi Informatika \\ Fakultas Teknik Universitas Muhammadiyah Tangerang \\ J1. Perintis Kemerdekaan 1/33 Cikokol Kota Tangerang \\ e-mail: nurhayati09011@ft-umt.ac.id, lilysrimulyati@gmail.com
}

\begin{abstract}
In implementing the distribution of covid 19 social assistance, the village government experienced many difficulties and protests from the community, in conducting data collection, the local RT still used the conventional system. The research objective was to find out the covid 19 social assistance system in Tapos village and the problems faced in its application. Data collection methods using observation techniques, library research and interviews. System base methodology uses the SWOT technique (Strength, Weaknesses, Opportunities and Threats). The design methodology used is the UML (Unified Modeling Language) analysis approach, and the system development method uses a waterfall which consists of requirements analysis, system design, implementation and unit testing, integration and system testing, and operation and maintenance.
\end{abstract}

Keywords: Feasibility of social assistance, Covid 19, SWOT, UML, Waterfall

\begin{abstract}
Abstrak
Dalam pelaksanaan penyaluran bantuan sosial covid 19 pemerintah desa mengalami banyak kesulitan dan protes dari masyarakat, dalam melakukan pendataan yang dilakukan pihak RT setempat masih menggunakan sistem konvensional. Tujuan penelitian untuk mengetahui sistem bantuan sosial covid 19 di desa tapos dan masalah yang dihadapi dalam penerapannya. Metode pengumpulan data menggunakan teknik pengamatan, penelitian perpustakaan dan wawancara. Metodologi alasisis sistem menggunakan teknik SWOT (Strength, Weaknesses, Opportunities dan Threats). Metodologi perancangan yang digunakan yaitu dengan pendekatan analisa UML (Unified Modeling Languange), dan metode pengembangan sistem menggunakan waterfall yang terdiri dari analisa kebutuhan, desain sistem, implementation and unit testing, integration and system testing, dan operation and maintenance.
\end{abstract}

Kata Kunci: Kelayakan bantuan sosial, Covid 19, SWOT, UML, Waterfall

\section{PENDAHULUAN}

Dalam pelaksanaan penyaluran bantuan sosial covid 19 pemerintah desa mengalami banyak kesulitan dan protes dari masyarakat, dalam melakukan pendataan yang dilakukan pihak RT setempat masih menggunakan sistem konvensional. Contohnya 
pendataan yang menggunakan kertas dan metode penyimpanan berkas pengajuan bantuan dan penerima bantuan berbentuk buku.

Dari latar belakang masalah diatas, peneliti tertarik untuk mengetahui lebih lanjut tentang sistem informasi kelayakan bantuan sosial covid 19 yang ada pada Desa Tapos dan menyusunnya dalam bentuk tugas penelitian yang diberi judul

\section{"RANCANG BANGUN SISTEM INFORMASI KELAYAKAN BANTUAN SOSIAL COVID 19 BERBASIS WEB DI DESA TAPOS “.}

\section{Jenis Penelitian}

\section{METODE PENELITIAN}

Jenis penelitian ini adalah penelitian kualitatif deskriptif, yaitu data yang dikumpulkan berbentuk gambar, kata-kata tertulis atau lisan dari narasumber yang diwawancarai dan diamati.

\section{Metode Pengembangan Sistem}

Dalam pembuatan sistem ini penulis menggunakan metode pengembangan sistem yaitu metode waterfall. Berikut penulis memaparkan rencana yang dilakukan pada tiap-tiap tahapan menurut metode pengembangan sistem yang telah dipilih, yaitu:

\section{Analisis kebutuhan}

Tahapan ini merupakan proses dimana penulis mengumpulkan kebutuhan untuk sistem yang akan dibuat seperti data penerima bansos, tujuannya untuk mempermudah membuat program. Penulis mendapatkan data penerima bansos covid 19 dari observasi dan hasil wawancara dengan petugas bagian bansos di Kantor Desa Tapos.

2. Desain Sistem

Dalam tahapan ini Desain sistem merupakan tahap penyusunan proses, data, aliran proses, dan hubungan antar data yang paling optimal untuk menjalankan proses antrian dan memenuhi kebutuhan sesuai dengan hasil analisis kebutuhan. Di tahap ini, penulis menentukan dan membuat desain sistem dan aliran proses dari sistem yang akan dirancang.

3. Implementation and Unit Testing

Pada tahap ini merupakan tahap untuk mengubah desain yang telah dibuat menjadi sebuah sistem yang dapat berjalan sesuai dengan kebutuhan. Tahap ini merupakan pengkodean dari desain ke dalam suatu bahasa pemrograman. Dalam sistem ini desain yang telah dibuat dikodekan dengan menggunakan salah satu bahasa pemrograman.

Data yang diperoleh dari suatu desain sistem yang telah dirancang akan diubah ke dalam bahasa komputer atau diubah menjadi kode.

Untuk tahap ini, penulis mulai melakukan pengkodean dan bahasa pemrograman yang telah ditentukan untuk menciptakan desain sistem dan aliran proses yang telah dirancang sebelumnya.

4. Integration and System Testing

Agar sistem aplikasi yang telah dibuat dapat berjalan dengan baik dan memberikan hasil yang optimal, maka perlu proses pengujian. Pendekatan yang penulis gunakan adalah blackbox, dimana program dianggap sebagai suatu "blackbox", pengujian berbasiskan spesifikasi, kebenaran perangkat lunak yang diuji hanya dilihat berdasarkan keluaran yang dihasilkan dari data atau kondisi masukan yang diberikan untuk fungsi yang ada tanpa melihat bagaimana proses untuk mendapatkan keluaran tersebut. Penulis melakukan testing pada aplikasi yang telah dibuat untuk menguji apakah sistem telah berjalan sesuai dengan yang diinginkan.

5. Operation and Maintenance

Merupakan tahap perawatan sistem yang telah dikembangkan seperti perawatan 
perangkat lunak, perawatan perangkat keras dan media lain yang berhubungan dengan komputer. Pada tahap ini pula harus dijaga performance perangkat lunak agar berjalan dengan baik. Pada tahap akhir ini, penulis melakukan perawatan mulai dari software dan hardware agar performa dari sistem yang telah dibuat tetap stabil.

\section{Gambaran Sistem Berjalan}

\section{HASIL DAN PEMBAHASAN}

Sistem bantuan sosial covid 19 yang berjalan saat ini masih menggunakan sistem konvensional. Contohnya dimulai dari pendataan yang menggunakan kertas oleh RT, verifikasi oleh Staff Desa dengan cara mengecek data warga yang ditulis oleh RT dikertas, dan data penyimpanan berkas pengajuan bantuan dan penerima bantuan disimpan dalam file box.

\section{Perancangan Sistem Usulan}

Berdasarkan pembahasan pada bab sebelumnya, maka di usulkan suatu perancangan sistem yang baru bertujuan untuk memberikan solusi yang lebih baik dari sistem yang sebelumnya. Berikut perancangan sistem usulan :

Use Case Diagram Usulan Kelayakan Bantuan Sosial Covid 19

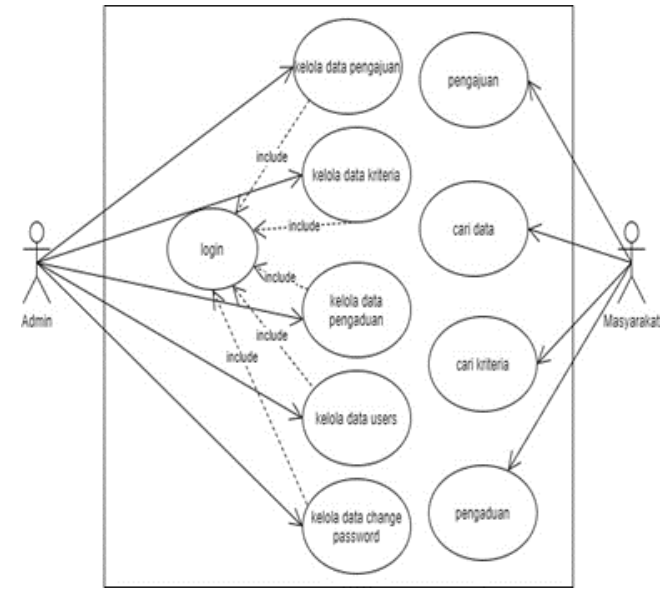

Gambar 1 Use Case Kelayakan Bantuan Sosial Covid 19 


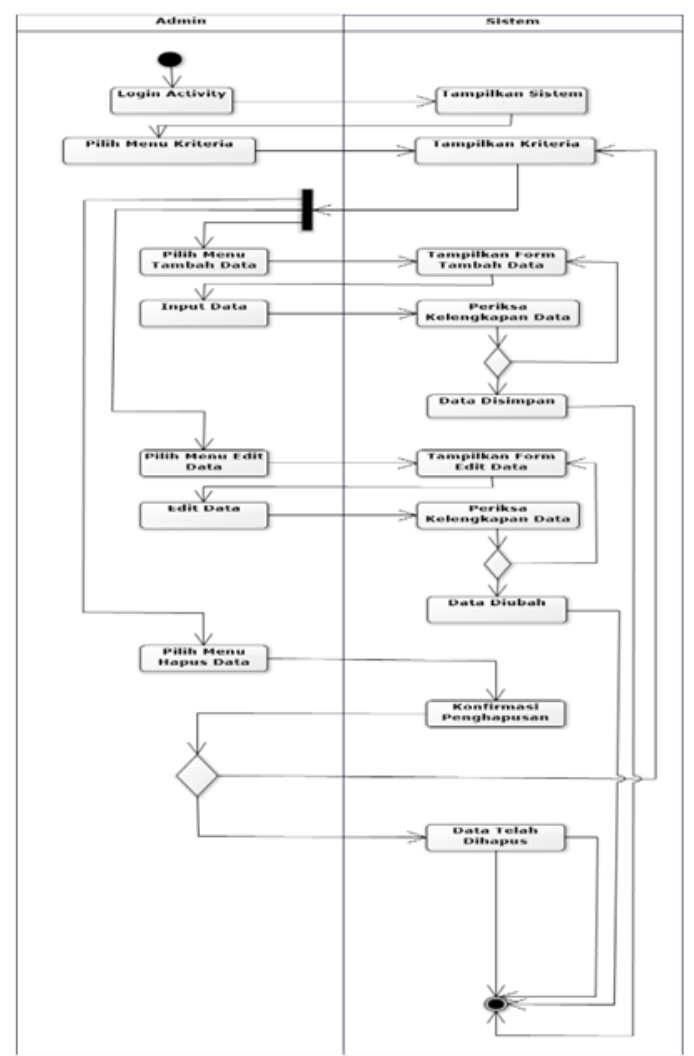

Gambar 2 Activity Diagram Kelola Data Kriteria

\section{Implementasi Sistem}

1. Login

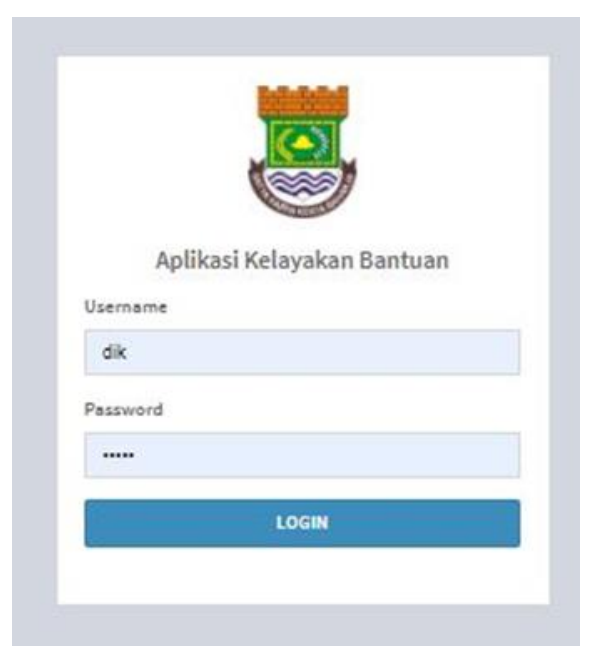

Gambar 3 Halaman Login

Subyek yang berhak untuk login pada gambar 3 Halaman login di atas adalah Admin Admin adalah administrator yang mengelola data sistem informasi kelayakan bantuan sosial covid 19. 
2. Menu Utama Masyarakat

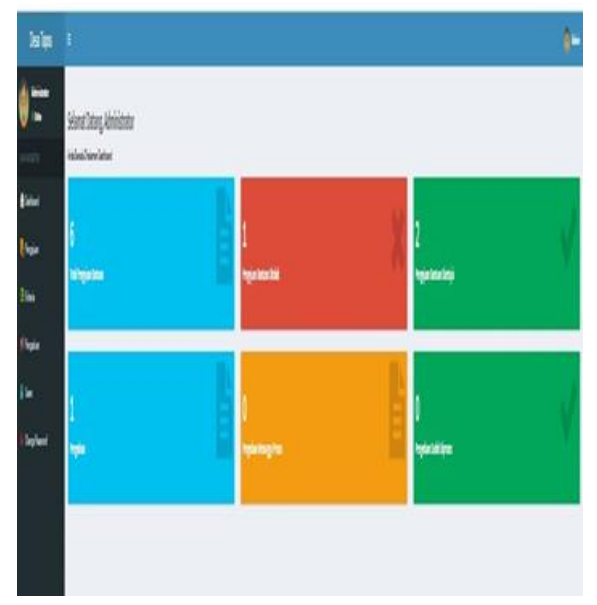

Gambar 4 Halaman Menu Utama (Masyarakat)

Pada gambar 4 diatas yang menjelaskan tentang halaman menu utama (Masyarakat) dari aplikasi. Halaman menu utama (Masyarakat) tersebut masyarakat bisa melakukan input pengajuan, cari data penerima bantuan, cari data pengajuan bantuan, lihat info kriteria, input pengaduan.

3. Menu Utama Admin

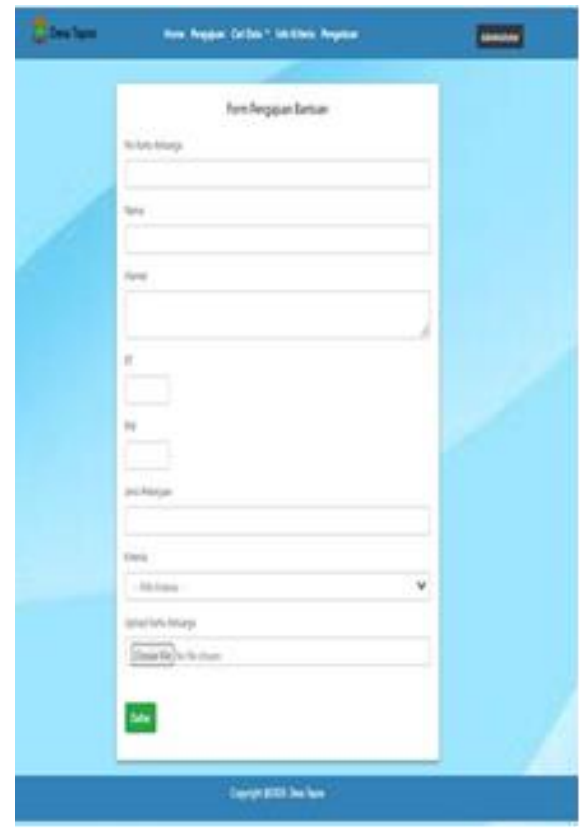

Gambar 5 Halaman Utama Admin

Pada gambar 5 diatas yang menjelaskan tentang halaman menu utama (admin) dari aplikasi. Halaman menu utama (admin) tersebut masyarakat bisa melakukan kelola data pengajuan, kelola data kriteria, kelola data pengaduan, kelola data user, dan kelola data password. 
JT : Jurnal Teknik

P-ISSN: 2302-8734

E-ISSN: 2581-0006
Vol. 10 No. 1 Th. 2021

Halaman : 98 - 108 Januari $2021 \ldots$

4. Input pengajuan (masyarakat)

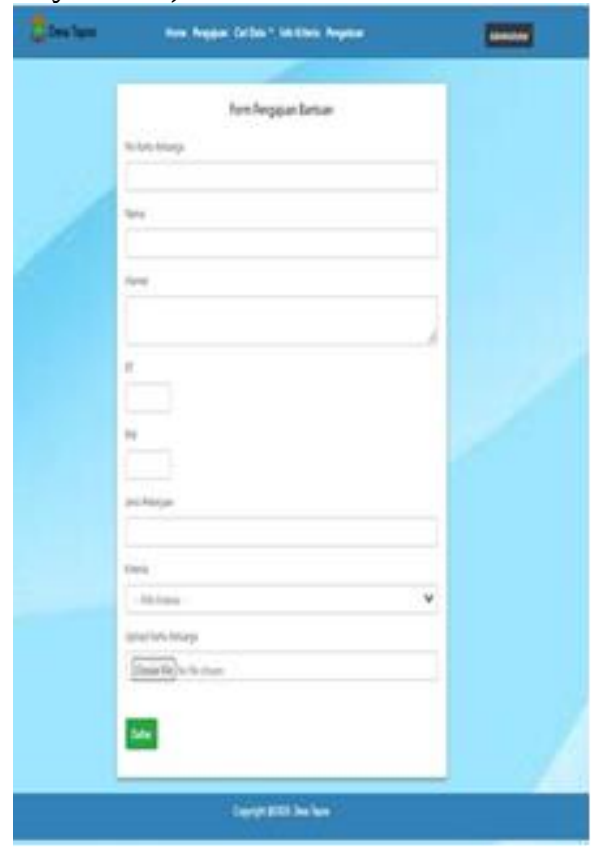

Gambar 6 Halaman input pengajuan (masyarakat)

Gambar 6 tentang penginputan data warga yang ingin mengajukan bantuan sosial covid 19.

1. Data Penerima Bantuan (masyarakat)

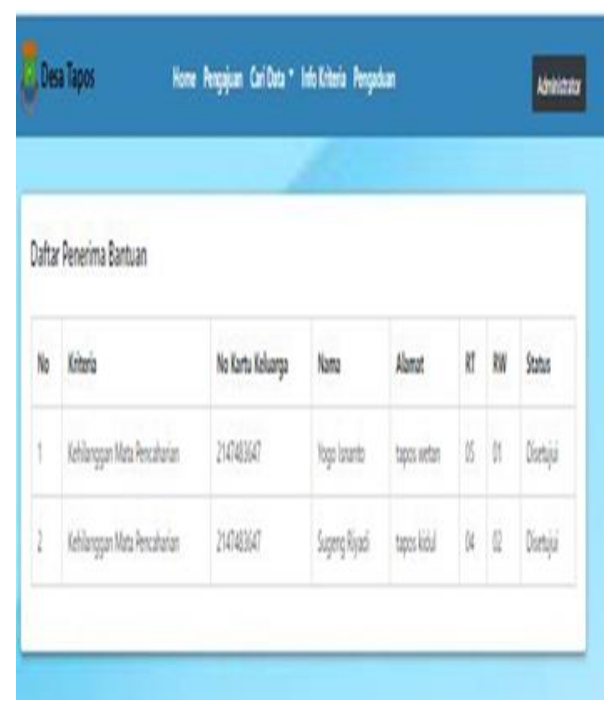

Gambar 7 Halaman Data Penerima Bantuan

Gambar 7 tentang data penerima bantuan yang telah disetujui dan ditolak oleh admin atau masih dalam proses pengajuan. 
2. kelola data pengajuan (admin)

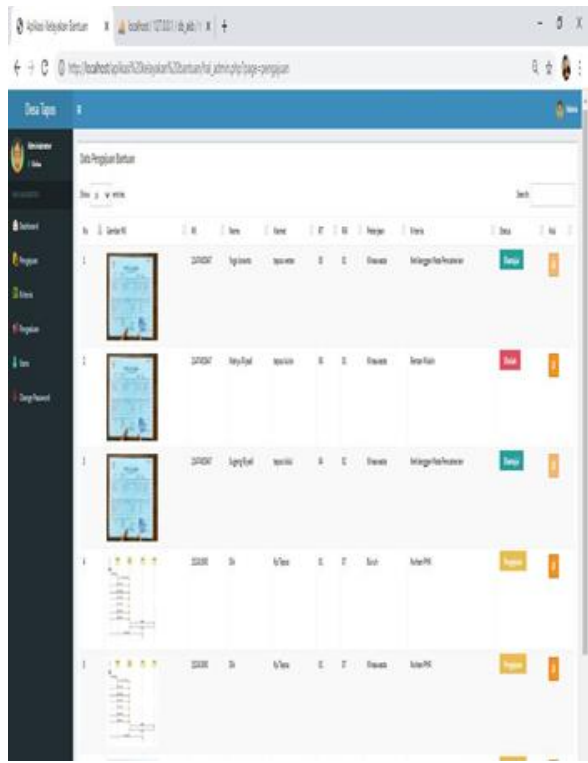

Gambar 8 Halaman pengajuan

Gambar 8 tentang halaman pengajuan dimana admin memproses data pengajuan yang telah diinput oleh masyarakat dengan mengubah status menjadi disetujui atau ditolak, dan admin juga dapat menambahkan data pengajuan secara langsung juga dapat menghapus data yang tidak perlu

3. Input Pengaduan (masyarakat)

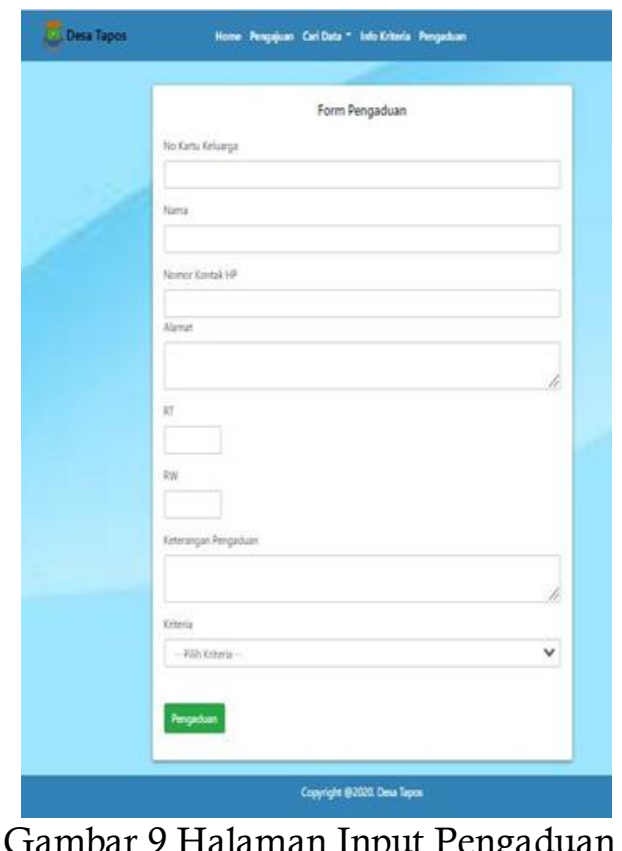

Gambar 9 Halaman Input Pengaduan 
JT : Jurnal Teknik

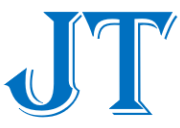

Vol. 10 No. 1 Th. 2021

P-ISSN: 2302-8734

Halaman : 98 - 108

E-ISSN: 2581-0006

Januari $2021 \ldots$.

Gambar 9 tentang penginputan data pengaduan oleh warga yang ingin mengadukan seputar pelayanan pelaksanaan bantuan sosial covid 19 .

4. Kelola Data pengaduan (admin)

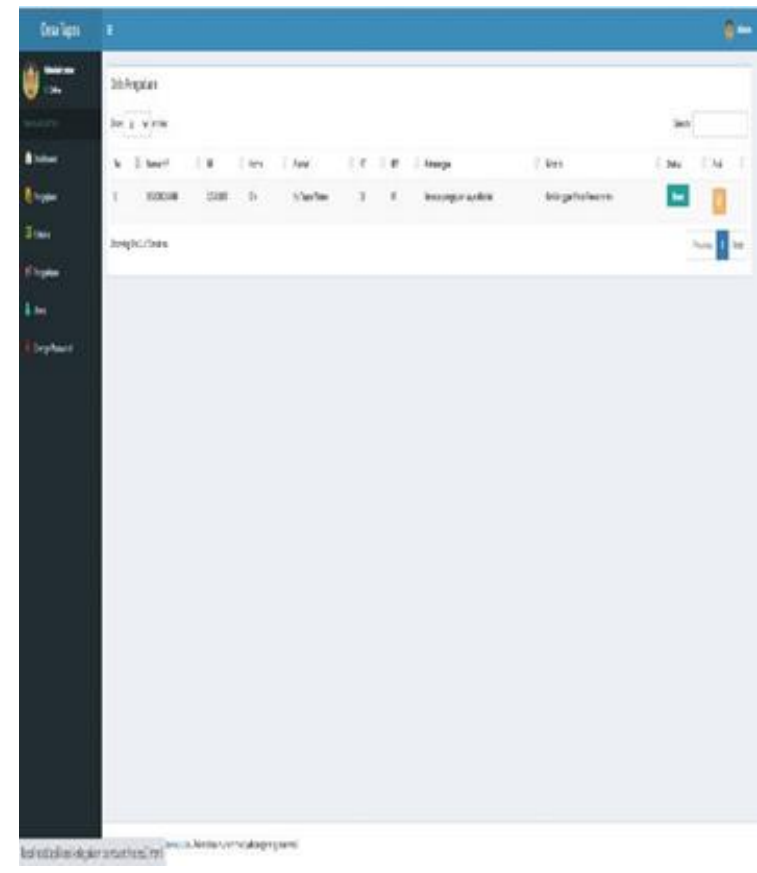

Gambar 10 Halaman Kelola Data Pengaduan

Gambar 10 tentang kelola data pengaduan yaitu data yang telah diinput oleh masyarakat akan ditanggapi melalui kontak telpon dan data yang telah ditanggapi lalu ditandai dan admin juga dapat mencetak data pengaduan yang telah diproses.

5. Info Kriteria

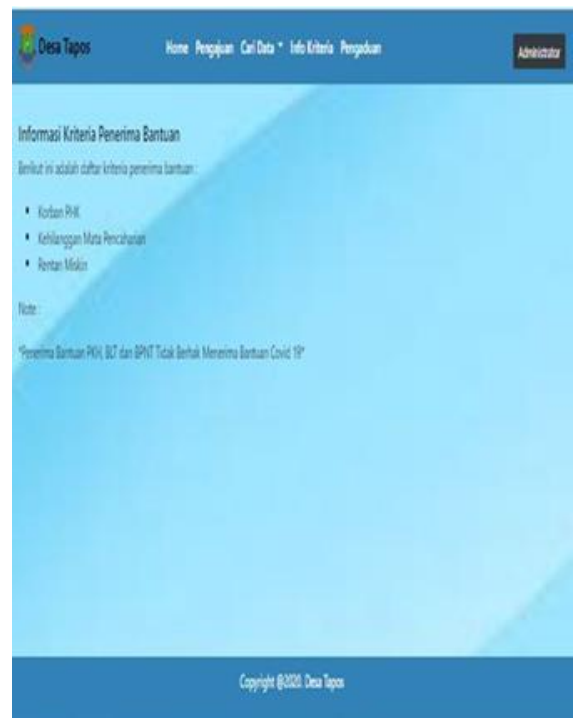

Gambar 11 Halaman Info Kriteria (Supplier)

http://jurnal.umt.ac.id/index.php/it/index

JT - 105 
JT : Jurnal Teknik

P-ISSN: 2302-8734

Vol. 10 No. 1 Th. 2021

E-ISSN: 2581-0006

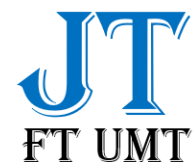

Halaman : 98 - 108

Januari $2021 \ldots$.

Pada gambar 11 diatas yang menjelaskan tentang halaman info kriteria yang diharapkan sebagai informasi kepada masyarakat sehingga masyarakat mengatahui syarat pengajuan bantuan covid 19 dan tidak terjadi salah paham.

6. Kelola Data Kriteria (Admin)

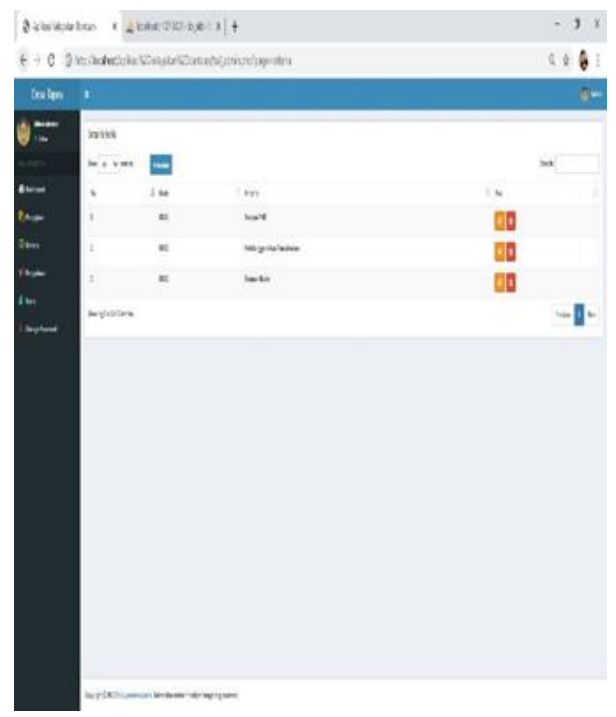

Gambar 12 Halaman Kelola Data Kriteria

Gambar 12 tentang halaman kelola data kriteria (admin) yaitu proses admin menambah mengubah atau menghapus data kriteria.

Kelola Data User

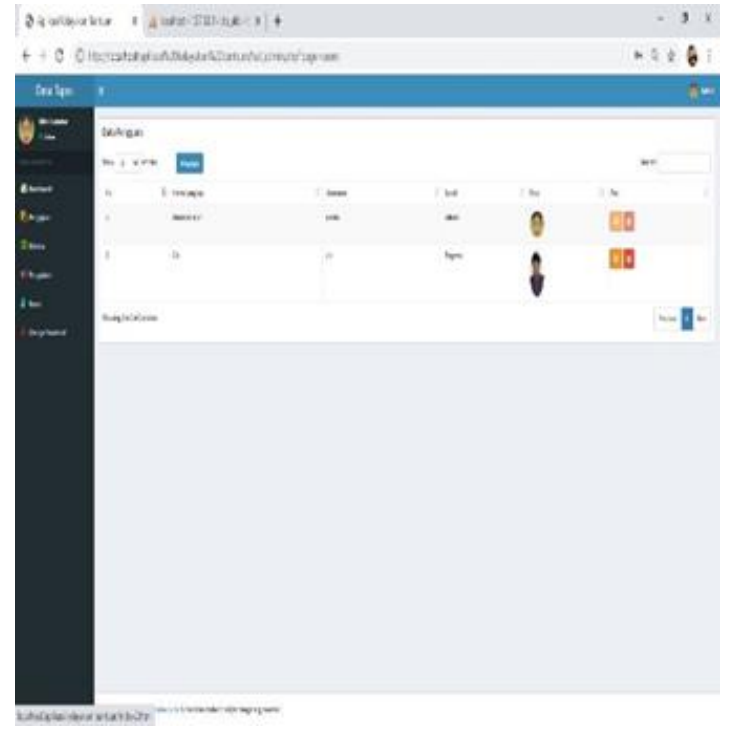

Gambar 13 Halaman Kelola Data User

Gambar 13 tentang kelola data user dimana admin dapat menambahkan, menghapus, atau menghapus data user. 
Kesimpulan

Berdasarkan hasil penelitian dan pembahasan maka dapat diambil beberapa kesimpulan sebagai berikut:

1. Prosses pengolahan data pengajuan bantuan dan pengolahan data penerima bantuan pada Desa Tapos yang sedang berjalan saat ini masih menggunakan metode konvensional dalam pembuatannya karena menggunakan metode penulisan dalam kertas, prosses verifikasi menggunakan data yang ditulis didalam kertas, dan penyimpanan data pengajuan bantuan juga data penerima bantuan menggunakan file box.

2. Perancangan pembangunan sistem informasi kelayakan bantuan sosial covid 19 berbasis web di Desa Tapos dimulai dari pembuatan diagram UML yang terdiri dari lima buah diagram yaitu usecase diagram, activity diagram, statechart diagram, sequence diagram dan class diagram sebagai awal rancangan sistem yang akan dibuat, selanjutnya dibuatlah sistem informasi kelayakan bantuan sosial covid 19 dengan bahasa pemrograman php. Mysql juga digunakan sebagai media pengelolaan database yang bisa mengelola data pengajuan dan penerimaan agar dapat tersimpan dengan baik.

\section{DAFTAR PUSTAKA}

Agung Baitul Hikmah. dkk. 2015. Cara Cepat Membangun Website dari Nol Studi Kasus : Web Dealer Motor. Yogyakarta : CV. Andi Offset

Ardhana, YM Kusuma. 2012. PHP Menyelesaikan Website 30 Juta. Jakarta: Jasakom

Azhar, Susanto. 2017. Sistem Informasi Akuntansi. Cetakan pertama. Lingga Jaya. Bandung.

Egi Julian. 2016 Sistem Informasi Bantuan Sosial Bagian Kesra Setda Kabupaten Sumedang, Vol. 10 No.2, November.

Fahmi, Irham (2014). Manajemen Kepemimpinan Teori \& Aplikasi. Bandung: ALFABETA.

Herlawati Widodo Pudjo Prabowo, Menggunakan UML, Informatika, Bandung, 2011

Kadir, Abdul. (2014). Pengenalan Sistem Informasi Revisi. Yogyakarta: Andi.

Kamaruddin, 2016 RANCANG BANGUN SISTEM INFORMASI DISTRIBUSI BANTUAN SOSIAL BERAS MISKIN (STUDI KASUS KECAMATAN BINAMU KABUPATEN JENEPONTO), Vol.1 No.1, Oktober.

O'Brien \& Marakas. (2013). Management Information Systems. Sixteenth Edition. New York: McGraw-Hill/Irwin.

Romney, Marshall B. dan Paul John Steinbart. (2014). Sistem Informasi Akuntansi. Jakarta: Salemba Empat.

Suparno 2018 ANALISIS PEMBERIAN BANTUAN SOSIAL PROGRAM KELUARGA HARAPAN TERHADAP PRESTASI BELAJAR ANAK DI KECAMATAN SEPAUK, Vol. 3 No 2.

Sibero, Alexander F.K . 2013. Web Programming Power Pack. Yogyakarta : Mediakom.

Tata Sutabri. 2012 Analisis Sistem Informasi.Andi. Yogyakarta.

Pressman, R. (2010). Rekayasa Perangkat Luna:Black-Box Testing. Yogyakarta: Andi.

Purbadian, Yenda. 2016. Trik Cepat Membangun Aplikasi Berbasis Web dengan Framework CodeIgniter. Yogyakarta: Andi Offset.

Widodo, Prabowo.P,Dkk, 2011, Pemodelan Sistem Berorientasi Obyek Dengan UML, Graha ilmu, Yogyakarta.

https://www.kemkes.go.id/folder/view/full-content/structure-faq.html diakses pada 
JT : Jurnal Teknik

Vol. 10 No. 1 Th. 2021

P-ISSN: 2302-8734

Halaman : 98 - 108

E-ISSN: 2581-0006 Januari $2021 \ldots$

tanggal 21 september 2020

https://pkh.kemsos.go.id/dokumen/DOCS20181009100206.pdf diakses pada tanggal 21 september 2020 